\title{
Clinical Features and Disease Course of Primary Angioedema Patients in a Tertiary Care Hospital
}

This article was published in the following Dove Press journal:

Journal of Asthma and Allergy

\author{
Amalie Hartvig Pall (D' \\ Anne Fog Lomholt ${ }^{\prime}$ \\ Christian von Buchwald (iD ${ }^{\prime}$ \\ Anette Bygum (iD) ${ }^{2-4}$ \\ Eva Rye Rasmussen (D) ${ }^{1,2}$ \\ 'Department of Otorhinolaryngology, \\ Head and Neck Surgery and Audiology, \\ Rigshospitalet, University Hospital of \\ Copenhagen, Copenhagen, Denmark; \\ ${ }^{2}$ OPEN - Open Patient Data Explorative \\ Network, Odense University Hospital, \\ Odense, Denmark; ${ }^{3}$ Department of \\ Dermatology and Allergy Centre, \\ Odense University Hospital, Odense \\ 5000, Denmark; ${ }^{4}$ Department of Clinical \\ Research, University of Southern \\ Denmark, Odense 5000, Denmark
}

Correspondence: Amalie Hartvig Pall Department of Otorhinolaryngology, Head and Neck Surgery and Audiology, Rigshospitalet, University Hospital of Copenhagen, Blegdamsvej 9B, Copenhagen 2100, Denmark Email amalie.hartvig.pall.03@regionh.dk
Purpose: To give a better understanding of primary AE, the clinical characteristics and the possible therapeutic approaches.

Background: Angioedema (AE) is a non-pitting, non-itching swelling of skin or mucosa. The symptom can become life-threatening if located in the airways. Primary (monosymptomatic) AE is a manifestation of several different diseases and the diagnosis is not always straight-forward. The aetiological and pathophysiological factors of primary AE are not completely clarified. There is a need for further investigation.

Patients and Methods: This was a retrospective cohort study of patients referred to an outpatient dermatology clinic in a tertiary care hospital for clinical assessment due to primary AE in the period from 1996 to 2014.

Results: A total of 315 patients were identified with primary AE. The most frequent subtype was idiopathic $\mathrm{AE}(42.5 \%)$ and the second most common was angiotensin-converting enzymeinhibitor (ACEi)-induced AE (31.1\%). Three patients were diagnosed with hereditary $\mathrm{AE}$ and one patient was diagnosed with acquired C1-inhibitor deficiency. At least 107 (34.0\%) patients had established histaminergic AE. More than $1 / 3$ of the patients were treated in an emergency room or hospitalized due to AE. A $98.1 \%$ of patients had experienced $\mathrm{AE}$ in the head and neck area. Seven patients were in the need of acute airway intervention. Six of these had ACEi-induced AE. Female sex and smoking were found to be risk factors for developing AE.

Conclusion: The most frequent diagnoses were histaminergic-, non-histaminergic idiopathic $\mathrm{AE}$ and ACEi-induced $\mathrm{AE}$, whereas complement $\mathrm{C} 1$-inhibitor deficiency was rare. Histaminergic AE made up a substantial group of patients with primary AE. Even though there are different pathophysiological causes of AE, many cases have overlapping clinical manifestations, which make diagnosis and treatment difficult.

Keywords: primary angioedema, urticaria, hereditary angioedema, angiotensin-converting enzyme inhibitors, bradykinin

\section{Background}

Angioedema (AE) is a non-pitting, self-limiting swelling of skin and mucosa, which can become life-threatening when located in the airways. The condition is caused by an increase in vascular permeability due to different mediators. ${ }^{1}$ More than one-third of AE cases are estimated to be associated with urticaria. ${ }^{2,3} \mathrm{AE}$ and urticaria can be seen as different manifestations of common pathological processes. AE is located to the deeper layer of the skin and the maximum duration of the symptom is 7 days, whereas urticaria is located in the superficial dermis with a duration of 1-24 hours. ${ }^{4,5}$

AE can be defined as either acquired (AAE) or hereditary (HAE). AAE can be further sub-divided into several categories: idiopathic histaminergic AE, idiopathic 
non-histaminergic $\mathrm{AE}, \mathrm{ACEi}$-induced $\mathrm{AE}$ and acquired complement C1-inhibitor deficiency (C1-INH-AAE). An AAE subgroup associated with allergic reactions has been described by some studies. ${ }^{1,6}$ HAE is categorized into HAE with C1-INH deficiency (C1-INH-HAE) and HAE with normal $\mathrm{C} 1-\mathrm{INH}{ }^{7}$ The former is associated with mutations in the SERPING1 gene whilst the latter has been associated with mutations of the following genes: Factor XII, angiopoietin-1, plasminogen and kininogen $1 .^{8,11}$

C1-INH-HAE is an autosomal dominant hereditary disease with a prevalence of 1:50.000-1:71.000. ${ }^{12,13} \mathrm{C} 1$ INH-AAE has an even lower prevalence estimated as 1:10 of C1-INH-HAE patients. ${ }^{14,15}$ Histaminergic AE is caused by a release of histamine from mast cells and basophils and often presents with concomitant urticaria. ${ }^{1}$ Nonhistaminergic $\mathrm{AE}$ is associated with bradykinin and substance $\mathrm{P}$ release from the contact system and sensory nerve endings. ${ }^{16}$ Bradykinin-mediated $\mathrm{AE}$ is not associated with urticaria and does not respond to anti-allergic therapy with antihistamines, corticosteroids or adrenaline. ${ }^{1}$ Even though there are different pathophysiological causes of AE, many cases have overlapping clinical manifestations, which makes diagnosis and treatment difficult. ${ }^{17,18}$ Overall the treatment of $\mathrm{AE}$ depends on the symptoms. AE attacks are self-limiting and last 1-7 days without medical treatment. Recurrent AE attacks are associated with a significant reduction in health-related quality of life due to limitations in daily activity, fear of suffocation and in some cases worries about heritability. ${ }^{19}$

The current treatment of acute $\mathrm{AE}$ in patients who have not been diagnosed with C1-INH deficiency consists of corticosteroids, antihistamines and in severe cases adrenalin. Histamine is the predominant cause of $\mathrm{AE}$ and the current acute first line of treatment thus favours patients with histaminergic AE. ${ }^{20}$ Patients with swelling attacks due to $\mathrm{C} 1$ INH deficiency can effectively be treated with C1-INH concentrate or a bradykinin receptor antagonist. ${ }^{21,23}$

The objective of this study is to describe the clinical characteristics of patients found to have primary $\mathrm{AE}$ in order to give a better understanding of the disease.

\section{Patients and Methods}

\section{Study Population}

This was a retrospective observational cohort study of patients with primary AE. Seven hundred and thirty-four patients were referred to a dermatology department in a tertiary care hospital due to a suspicion of AE between
01-01-1996 and 31-12-2014. Patients were included if they had experienced $\mathrm{AE}$ at least once. The patients were selected based on International Classification of Diseases Version 10 (ICD-10) diagnostic codes possibly linked to the AE diagnosis: DT78.3 Quincke's edema, DL50 Urticaria, or DD84.1A Hereditary angioedema. One hundred and thirty-two patients were excluded due to insufficient clinical information. Seventy-four patients were excluded due to missing concluding $\mathrm{AE}$ diagnosis by a dermatologist (defined as DT78.3 Quincke's edema or DD84.1A Hereditary angioedema). Four patients were excluded due to other underlying factors of swellings such as Melkersson-Rosenthal syndrome or Panniculitis. Two hundred and nine patients were excluded due to concomitant urticaria (DL50.8A Chronic urticaria, DL50.8B Urticaria recidivans, DL50.8D Urticaria acuta, DL50.8E Urticaria due to pressure, DL50.1 Idiopathic urticaria, DL50.8 Other forms of urticaria). A total of 315 patients were diagnosed with primary AE (Figure 1).

\section{Data Extraction}

Baseline characteristics such as sex, age, underlying cause of AE, ICD-10 codes, anatomical site of AE, daily drug intake, comorbidities, treatment, hospitalization and follow-up time were obtained from patient medical records in an electronic data system. The follow up time was calculated from the first visit to ended clinical investigation by a dermatologist.

\section{Data Sources}

The drug sales information for the Danish background population was acquired from the Register of Medicinal Product Statistics (Medstat.dk) for comparative statistical analysis. ${ }^{24}$ This registry dates back to 1999 ; hence, data from the background population was only to be found from 1999 to 2014. Eight patients in the cohort were referred before 1999 and were excluded in the analysis of daily drug intake only. Drug intake information for the patients was obtained for 308 patients. Comorbidity in the background population was extracted from Sundhed og Sygelighed 2010 and hjertesvigt.dk. ${ }^{25,26}$

\section{Diagnosis}

Idiopathic $\mathrm{AE}$ was used as a diagnosis of exclusion by a dermatologist when no specific underlying factors of $\mathrm{AE}$ attacks were identified after clinical and biochemical assessment. Patients were diagnosed with idiopathic histaminergic $\mathrm{AE}$ if symptoms resolved following the 
734 patients referred to a dermatology department at a tertiary hospital between $1^{\text {st }}$ of January 1995 and $31^{\text {rd }}$ of December 2014

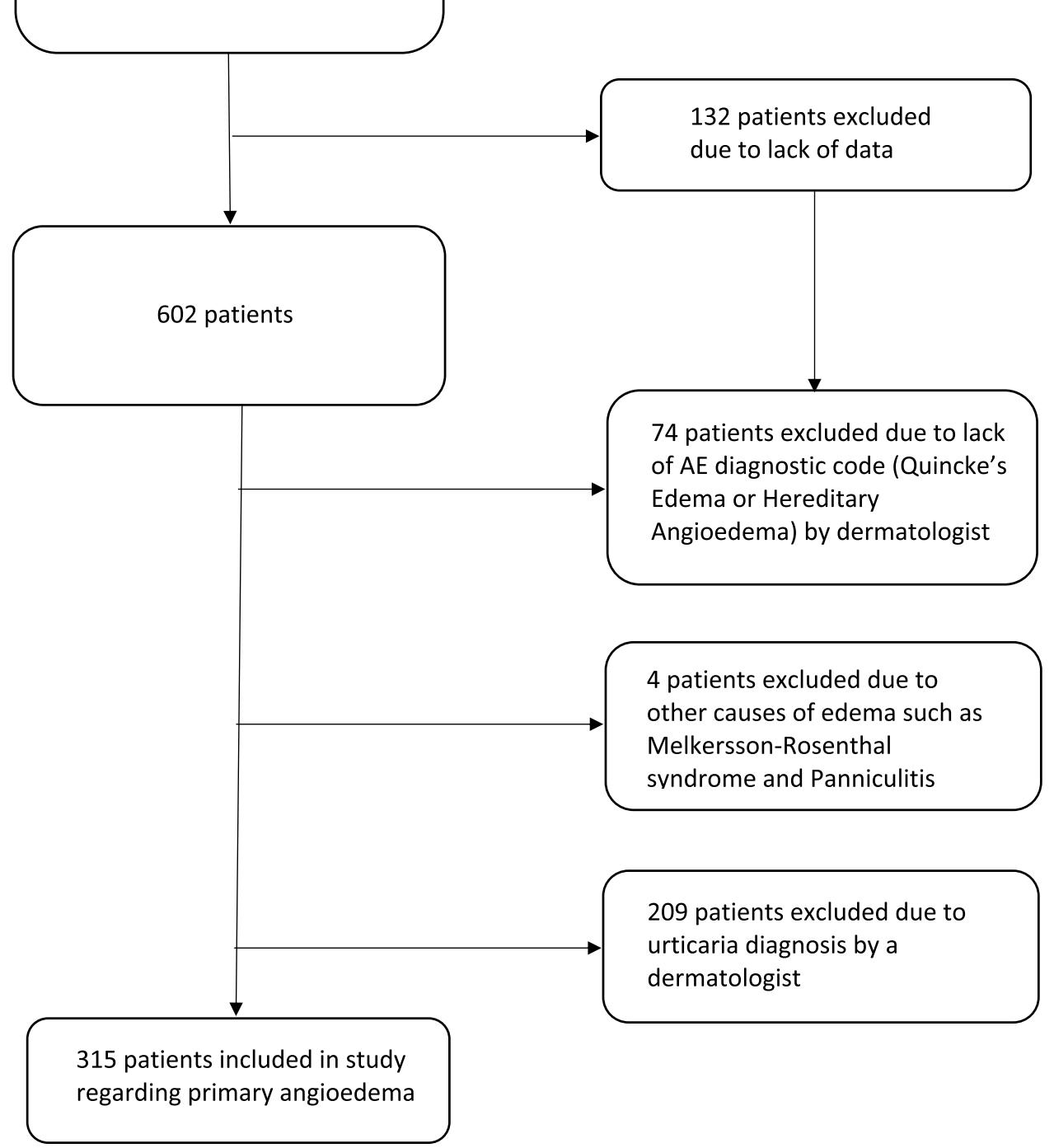

Figure I Patients with primary AE included in study. Seven hundred thirty-four patients referred to a dermatology department. Three hundred fifteen patients included in study.

continuous administration of antihistamines. Patients were diagnosed with idiopathic non-histaminergic AE diagnosis if symptoms did not resolve following continuous administration of high dose antihistamines. Patients were diagnosed with allergic AE if symptoms clearly occurred after allergen exposure and they had a positive skin prick test and/or positive histamine-release test of allergen-specific IgE. In other cases, a specific causative factor was identified, as the AE stopped after the elimination of a specific drug or underlying infection.
Patients were diagnosed with ACEi-induced AE if they received ACEi during an $\mathrm{AE}$ attack and no other cause of AE was found. Patients were diagnosed with NSAIDinduced AE if symptoms started after NSAID intake and improved after drug discontinuation. HAE and C1-INHAAE were diagnosed according to established criteria. ${ }^{7}$

\section{Statistical Analysis}

Analyses and calculations were performed in SPSS-24. A calculation of frequencies between the AE group and the 
general population was performed using the binomial distribution. Multivariate logistic regression was used to calculate the risk of admission due to different factors. $p$ values $\leq 0.05$ were considered statistically significant.

\section{Ethics}

This study was approved by the Danish Data Protection Agency (jr. number 14/35206) and the Danish National Board of Health (jr. number 3-3013-805/1/) as appropriate.

\section{Results}

Of 734 referred patients 315 were found to have primary AE (Figure 1). There were significantly more females (59.0\%) compared to males $(\mathrm{p}=0.001)$. The mean age at referral was 52.1 years. At $\mathrm{AE}$ onset the mean age was 48.2 years. The cohort mostly consisted of Caucasians (97.5\%). Data regarding smoking was available in 199 patients and 64 (32.2\%) were current smokers. Our study found significantly more current smokers amongst primary $\mathrm{AE}$ patients compared to the background population in a binomial distribution $(\mathrm{p}<0.001)$ (Table 1$)$.

Table I Basic Data of 315 Patients with Primary Angioedema in the Cohort

\begin{tabular}{|c|c|c|c|}
\hline Patients, $\mathbf{n}$ & \multicolumn{3}{|l|}{315} \\
\hline Male; Female ratio & \multicolumn{3}{|c|}{$129 ; 186$} \\
\hline Period of referral & \multicolumn{3}{|c|}{$0|-05-1996 ; 31-| 2-20 \mid 4$} \\
\hline Frequent smoker of 199 patients n (\%) & \multicolumn{3}{|c|}{$64(32.2)$} \\
\hline \multirow[t]{2}{*}{ Ethnicity } & \multicolumn{3}{|c|}{$\begin{array}{l}307 \text { caucasian, I Black, } 4 \\
\text { Asian, } 3 \text { unknown/others }\end{array}$} \\
\hline & & $95 \% \mathrm{Cl}$ & Range \\
\hline Age at referral, years & 52.1 & $50.2-54.0$ & $3-91$ \\
\hline Age at onset, years & 48.2 & $46.1-50.2$ & $0-86$ \\
\hline Family history of $A E$ or urticaria $n(\%)$ & \multicolumn{3}{|c|}{$\begin{array}{l}\text { Yes } 36(11.4) \\
\text { No } 247(78.4) \\
\text { Unknown } 32(10.2)\end{array}$} \\
\hline Localization of AE & \multicolumn{3}{|c|}{ Located in $\mathbf{n}(\%)$} \\
\hline$A E$ in head and neck area & \multicolumn{3}{|c|}{$309(98.1)$} \\
\hline Intra-abdominal $\mathrm{AE}$ & \multicolumn{3}{|c|}{ II (3.5) } \\
\hline Peripheral AE & \multicolumn{3}{|c|}{$62(19.7)$} \\
\hline Multifocal AE & \multicolumn{3}{|c|}{$64(20.3)$} \\
\hline
\end{tabular}

Abbreviations: $\mathrm{Cl}$, confidence interval; $\mathrm{AE}$, angioedema.
Idiopathic AE was most frequent (42.5\%). Eighty-two of 134 patients continued using antihistamines and could be classified as histaminergic or non-histaminergic AE. Among these patients, 59 (72\%) were idiopathic histaminergic $\mathrm{AE}$ and 23 (28\%) were idiopathic nonhistaminergic AE. For 52 patients the data was insufficient since the use of long-term antihistamines was not explicitly noted, or the follow-up time was too short to evaluate treatment response. Histaminergic AE was established in at least $107(34.0 \%)$ cases (idiopathic histaminergic $\mathrm{AE}$ and $\mathrm{AE}$ associated with an allergic reaction). The second most frequent cause of primary AE was ACEi usage. A total of 10 patients experienced $\mathrm{AE}$ as a result of NSAID usage (Figure 2). Nineteen patients $(6.0 \%)$ had $\mathrm{AE}$ due to a drug response associated with an allergic reaction caused by a drug that was not NSAID and ACEi (Figure 2). The drugs were penicillin, ${ }^{1}$ calciumantagonists, ${ }^{3}$ female hormonal therapy, ${ }^{2}$ simvastatin, ${ }^{2}$ serotonin reuptake inhibitor, ${ }^{2}$ metformin, ${ }^{1}$ allopurinol, ${ }^{1}$ donepezil, ${ }^{1}$ metoprolol, ${ }^{1}$ fluconazole,${ }^{1}$ and mefloquine. ${ }^{1}$ The rest of the patients experienced remission when several medications were discontinued, but the exact drug was not confirmed. ${ }^{3}$ Drug-related AE developed in $40.3 \%$ of the cases (NSAID, ACEi and drug response associated with an allergic reaction). For patients with infectionrelated $\mathrm{AE}$, the infections were tooth infection, otitis, herpes zoster, helicobacter pylori, tuberculosis, and mononucleosis. AE was also seen together with the autoimmune disease cutaneous lupus erythematosus and cancer-related with T-cell lymphoma. The other underlying factors of $\mathrm{AE}$ are displayed in Figure 2.

The medical treatment of $\mathrm{AE}$ was mainly anti-allergic (antihistamines, corticosteroids and adrenaline). However, $24(7.6 \%)$ patients were treated with other drugs for their AE attacks. Six patients were treated with tranexamic acid, six patients received a bradykinin receptor antagonist, and two patients were treated with C1-INH concentrate (Table 2).

Hospitalizations, as a result of $\mathrm{AE}$, were reported in $136(43.2 \%)$ patients. The days of hospitalization ranged between 1 and 35 with a mean number of 3.2 days. One hundred and twenty-seven patients (40.3\%) had been referred to the ER with a mean number of visits of 1.9 . Seven patients needed acute airway management due to swelling of the airways. Four of them females, three males, a mean age at onset 72 years. Six of them had ACEi-induced $\mathrm{AE}$, and one was $\mathrm{AE}$ associated with an allergic reaction. Four females and three males (Table 3). 


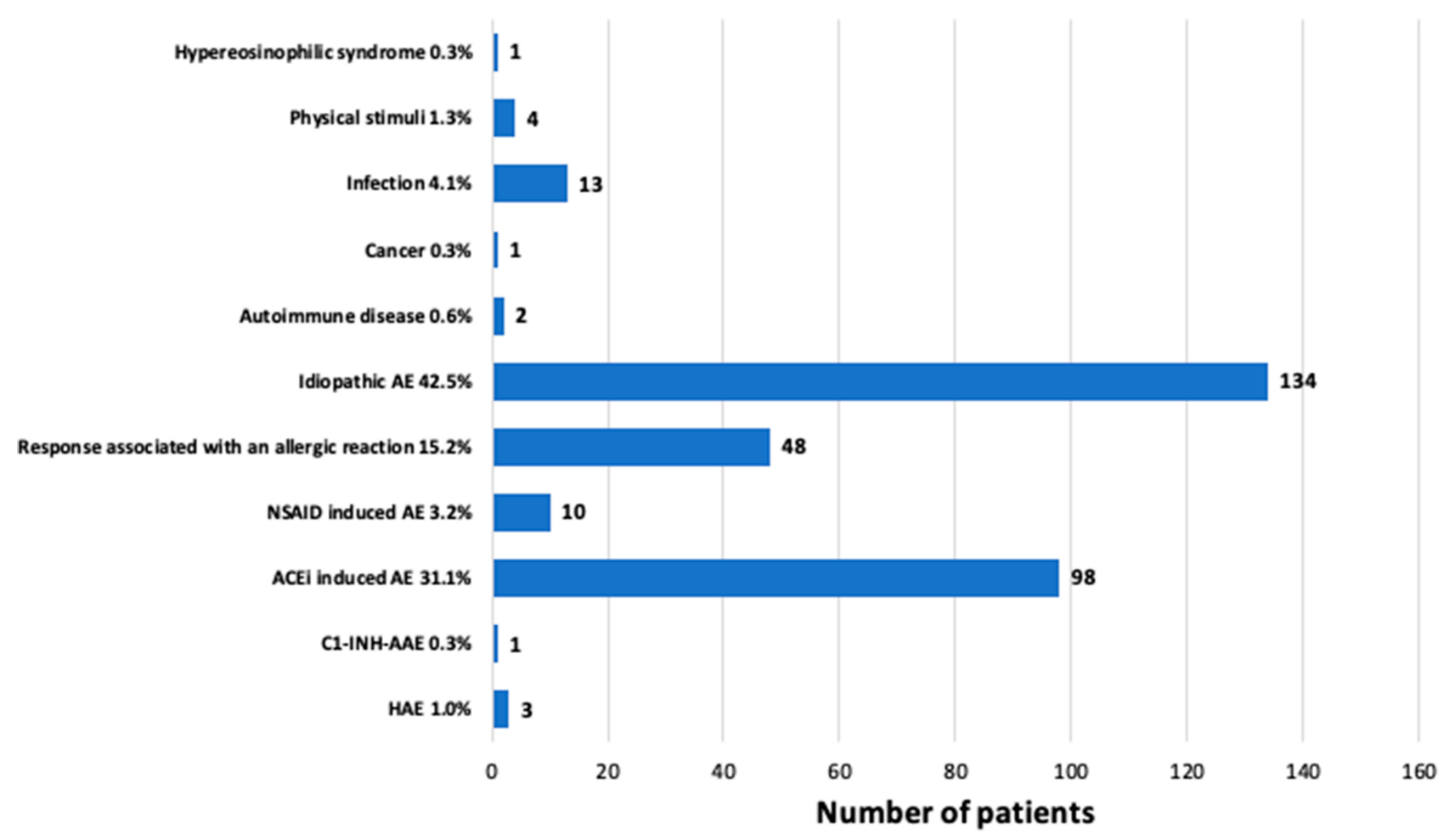

Figure 2 Underlying factors in 315 primary AE patients.

A parameter significantly associated with hospitalization was older age at referral. The odds ratio (OR) of hospitalization increased $3.0 \%$ for every year a patient increased in age. Comorbidities significantly associated with hospitalization were diabetes, hypertension, ischaemic heart disease, heart failure, allergy and asthma. Patients with ACEi-induced AE had a statistically significant greater risk of being admitted, whereas idiopathic $\mathrm{AE}$ patients had a statistically significant lower risk of being admitted (Table 4). The most frequent anatomical site of AE was the head and neck area (98.1\%) whereas abdominal AE was the least frequent site of $\mathrm{AE}$ (3.5\%). Patients with abdominal $\mathrm{AE}$ always manifested with $\mathrm{AE}$ in other locations as well. Sixty-two (19.7\%) patients had experienced peripheral AE. One-fifth (20.9\%) were reported with multifocal AE (Table 1).

General practitioners $(47.6 \%)$, internists $(20.0 \%)$, otorhinolaryngologists (10.5\%), and dermatologists (9.8\%) were the physicians who most often referred the patients to the dermatology department.

A $12.8 \%$ of patients did not have their follow-up time registered. A $9.1 \%$ of patients did not require any followup (follow-up $=0$ days). A $72.5 \%$ of patients had one follow-up appointment in the out-patient department with a mean follow-up period of 139.1 days. A 5.9\% attended the out-patient department at least twice with a mean follow up of 215 days. The mean follow-up time for all referrals was 146.7 days (95\% CI 128.4-170.2). The minimum follow-up time was 1 day, and the maximum followup time was 1415 days, ie, almost 4 years.

Five comorbidities were significantly more prevalent in the cohort compared to the background population: diabetes, hypertension, ischemic heart disease, heart failure and allergy. Allergy was the only significant prevalent comorbidity in the cohort group when patients with ACEiinduced $\mathrm{AE}$ were not a part of the calculation. Drug intake and comorbidities in the cohort and comparison to the background population are shown in Table 5 .

\section{Discussion}

In this study of 315 primary $\mathrm{AE}$ patients referred to a outpatient clinic in a tertiary care hospital, we found idiopathic histaminergic and non-histaminergic $\mathrm{AE}$ and $\mathrm{ACEi}-$ induced $\mathrm{AE}$ to be the most frequent underlying factors of $\mathrm{AE}$ in a tertiary referral centre. Most of the idiopathic cases (72\%) responded to antihistamines. The use of continuous antihistamines was not noted in the journals of 52 patients; hence, the number of histaminergic AE patients in the study population may be higher than noted. Thirty-four percent of patients were diagnosed with histaminergic AE, illustrating 
Table 2 Treatment of AE, Standard Therapy Treatment (Antihistamine, Corticosteroids and if Necessary Adrenaline/Epinephrine) and Second Line Drug Treatment of AE Incidents

\begin{tabular}{|c|c|c|c|}
\hline Acute Medical Treatment & Yes, n (\%) & No, n (\%) & Unknown, n (\%) \\
\hline Antihistamine & $287(91.3)$ & $19(6.0)$ & $9(2.9)$ \\
\hline Antihistamine efficacy & I84 (64.I) & $36(12.5)$ & $67(23.3)$ \\
\hline Corticosteroid & $199(63.2)$ & $109(34.6)$ & $6(1.9)$ \\
\hline Corticosteroid efficacy & $123(6 \mid .8)$ & $17(8.5)$ & $59(29.6)$ \\
\hline Adrenalin & $52(16.5)$ & $256(81.3)$ & $7(2.2)$ \\
\hline Adrenalin efficacy & $21(40.4)$ & $7(13.5)$ & $24(46.2)$ \\
\hline No standard drug administered (antihistamine, corticosteroids, adrenalin) & $17(5.4)$ & $289(91.7)$ & $9(2.9)$ \\
\hline Second line drug treatment of AE & $24(7.4)$ & \multicolumn{2}{|c|}{$\begin{array}{l}\text { Triggering factor related to second line } \\
\text { treatment of AE }\end{array}$} \\
\hline Bradykinin receptor antagonist (icatibant) & 6 & \multicolumn{2}{|c|}{ Five with $A C E \mathrm{E}-\mathrm{AE}$ and one with idiopathic $\mathrm{AE}$} \\
\hline Tranexamic acid & 6 & \multicolumn{2}{|c|}{$\begin{array}{l}\text { Two with } A E \text { due to physical stimuli, two patients with } \\
\text { idiopathic } A E \text {, one } A C E i A E \text { and one HAE patient }\end{array}$} \\
\hline Leukotriene D-4 receptor antagonist & 5 & \multicolumn{2}{|c|}{ Four with idiopathic $\mathrm{AE}$, one with allergy } \\
\hline Azathioprine & 3 & \multicolumn{2}{|c|}{ All idiopathic $\mathrm{AE}$} \\
\hline Glucocorticoids (inhalation) & 2 & \multicolumn{2}{|c|}{ Two with infection } \\
\hline $\mathrm{Cl}-\mathrm{INH}$ concentrate & 2 & \multicolumn{2}{|c|}{ One $\mathrm{HAE}$ and one with $\mathrm{AE}$ due to physical stimuli } \\
\hline Attenuated androgens (danazol) & 2 & \multicolumn{2}{|c|}{$\begin{array}{l}\text { One with } A E \text { due to physical stimuli and one with } \\
\text { idiopathic } A E\end{array}$} \\
\hline Beta-2 agonist & 2 & \multicolumn{2}{|c|}{ Both $\mathrm{ACEi} A \mathrm{E}$, one of these with asthma } \\
\hline Topical corticosteroid & I & \multicolumn{2}{|c|}{ Drug-induced AE } \\
\hline Antibiotics & I & \multicolumn{2}{|c|}{ One patient with infection } \\
\hline
\end{tabular}

Abbreviations: $A E$, angioedema; $n$, number of patients.

that histaminergic AE can also present without hives. Twentyone (6.7\%) patients developed AE related to specific external agents or concomitant diseases such as autoimmune diseases, cancer, infection, physical stimuli or Hypereosinophilic syndrome. This supports prior findings of how non-allergic external agents or concomitant diseases do sometimes manifest with primary $\mathrm{AE}^{4}$ Only three patients were diagnosed with HAE and one patient with C1-INH-AAE. This supports the consensus of C1-INH-AAE and -HAE as very rare underlying factors of primary $\mathrm{AE}{ }^{7,27} \mathrm{ACEi}-$ induced $\mathrm{AE}$ was seen

Table 3 Data Regarding ER Visits and Hospitalization

\begin{tabular}{|c|c|c|c|c|}
\hline & Yes, n (\%) & No, n (\%) & Unknown, n (\%) & \\
\hline Number of patients hospitalized & $136(43.2)$ & $179(56.8)$ & & \\
\hline \multirow[t]{2}{*}{ Airway management } & $7(2.2)$ & I 78 (55.6) & $135(42.2)$ & \\
\hline & Number of patients & Mean number & $\mathbf{C l}$ & Range \\
\hline Duration of admission, days & 129 & 3.2 & $2.4-3.9$ & $1-35$ \\
\hline Number of visits at ER & 127 & 1.9 & $1.6-2.1$ & $1-9$ \\
\hline
\end{tabular}

Abbreviations: $\mathrm{ER}$, emergency room; n, number of patients; $\mathrm{Cl}, 95 \%$ confidence interval. 
Table 4 Association Between Different Variables and the Need for Admission

\begin{tabular}{|c|c|c|c|c|}
\hline & OR & SE & Cl & p value \\
\hline Female sex & 0.677 & 0.231 & $0.430-1.065$ & 0.092 \\
\hline Current smoker & 1.295 & 0.304 & $0.7|4-2.35|$ & 0.395 \\
\hline Family history of $\mathrm{AE} /$ urticaria & 1.837 & 0.360 & $0.908-3.718$ & 0.091 \\
\hline Age at referral & 1.030 & 0.007 & $1.015-1.044$ & $<0.001 *$ \\
\hline Diabetes & 2.591 & 0.368 & I.259-5.329 & $0.010^{*}$ \\
\hline Hypertension & 2.110 & 0.234 & $1.334-3.337$ & $0.001 *$ \\
\hline Ischemic heart disease & 3.487 & 0.465 & I.402-8.674 & $0.007 *$ \\
\hline Heart failure & 4.113 & 0.677 & $1.091-15.504$ & $0.037^{*}$ \\
\hline Asthma & 3.104 & 0.403 & $1.409-6.838$ & $0.005 *$ \\
\hline Known allergy & 1.843 & 0.251 & $1.127-3.017$ & $0.015^{*}$ \\
\hline Atopic dermatitis & 0.908 & 0.507 & $0.336-2.45 I$ & 0.849 \\
\hline Allergic rhinitis & 1.049 & 0.357 & $0.521-2.110$ & 0.894 \\
\hline ACEi-induced AE & 1.959 & 0.247 & $1.207-3.180$ & $0.006 *$ \\
\hline Idiopathic-induced AE & 0.534 & 0.234 & $0.337-0.845$ & $0.007^{*}$ \\
\hline
\end{tabular}

Notes: *Statistically significant result in relation to OR of admission. Multivariate logistic regression analysis.

Abbreviations: OR, odds ratio; SE, standard error; $\mathrm{Cl}, 95 \%$ confidence interval.

in almost one-third of the cohort. Recent studies suggest an increase in $\mathrm{ACEi}$-induced $\mathrm{AE}$ as a result of an increase in ACEi prescriptions. ${ }^{28}$ ACEi-induced AE was first reported in 1984 and $0.1-2.2 \%$ of all ACEi users are estimated to develop AE. $^{29,31}$

Ten patients $(3.2 \%)$ had AE due to NSAIDs. It has been hypothesized that NSAID-induced AE is not an allergic reaction per se, but is due to excessive leukotriene production as a result of COX1 blocking. ${ }^{6,32}$ Eighteen (5.6\%) patients developed AE due to the use of another drug and were categorized as allergic.

Leeyaphan et al described NSAIDs and penicillin as drugs frequently associated with drug-induced AE. ${ }^{33,34}$ Calcium-antagonists, statins, metformin, metoprolol, female hormones, has also been reported in prior cases and are estimated as less frequent inducers of $\mathrm{AE}^{33,35,38}$ This study confirms existing evidence in the area, that nonACEi drug-induced AE does sometimes occur without concomitant hives.

The use of NSAIDs and female hormones in the background population was more frequent than seen in our study population. The underuse of female hormones is likely due to the higher mean age of the cohort group compared to the background population so especially birth control pills are less used in our cohort. Also, patients with $\mathrm{AE}$ are sometimes discouraged to use estrogens and often discouraged to use NSAIDs.

Our study found female sex to be a risk factor of primary AE. These results support prior findings of female predominance in AE patients. ${ }^{4,39}$ Five hundred and twenty-four patients with AE were identified, but $39.9 \%$ presented with concomitant urticaria. The primary AE: AE with concomitant urticaria-ratio was 1.5 , a ratio adjacent to 1.4 found by Mansi et al and 1.7 by Madsen et al. ${ }^{2,40}$ This study supports how histaminergic AE does not always manifest with urticaria, which makes it is difficult to differentiate between histaminergic and non-histaminergic AE based on clinical appearance. Why some histamine related AE patients present with urticaria and some do not are unknown. Eli et al have hypothesized how a greater activation of contact pathways and bradykinin production in primary $\mathrm{AE}$ leads to vasodilation of the deeper dermal layers, compared to AE patients with concomitant urticaria. $^{41}$

Most AE attacks were located in the head and neck area (98.1\%), these findings support other studies. ${ }^{4,40,42}$ Only seven patients were in the need of acute airway management. However, this should be taken seriously due to the high risk of asphyxiation. Six of these were ACEi-induced AE. This states a greater risk of airway intervention in ACEi-induced 
Table 5 Comorbidity and Daily Drug Intake in the Cohort Compared to the Background Population

\begin{tabular}{|c|c|c|c|c|}
\hline Daily Drug Intake & Yes, n (\%) & No, n (\%) & Background Population \% & p-value, Binomial Test \\
\hline Antihypertensive drugs & $132(42.9)$ & $176(57.1)$ & & \\
\hline ARB & $7(2.3)$ & $30 \mathrm{I}(97.7)$ & 3.80 & 0.099 \\
\hline ACEi & $98(31.8)$ & $210(68.2)$ & 5.64 & $<0.001 *$ \\
\hline Systemic corticosteroids & $8(2.6)$ & $300(97.4)$ & 3.27 & 0.321 \\
\hline Diabetic drugs & $28(9.0)$ & $280(90.9)$ & 2.90 & $<0.00 I^{*}$ \\
\hline NSAID (prescribed) & $25(8.1)$ & $283(91.9)$ & 15.3 & $<0.00 I^{*}$ \\
\hline Antihistamines & $44(14.3)$ & $264(85.7)$ & 4.90 & $<0.00 I^{*}$ \\
\hline Thrombocyte inhibitors & $54(18.0)$ & $254(82.0)$ & 8.00 & $<0.00 I^{*}$ \\
\hline Statins & $64(20.8)$ & $244(79.2)$ & 6.47 & $<0.00 I^{*}$ \\
\hline Drugs for asthma and chronic obstructive lung disease & $25(8.0)$ & $287(92.0)$ & 8.00 & 0.500 \\
\hline Osteoporosis drugs & $4(1.3)$ & $304(98.7)$ & 1.14 & 0.466 \\
\hline Opioids & $21(6.8)$ & $287(93.2)$ & 6.50 & 0.443 \\
\hline Anti-depressants & $29(9.4)$ & $279(90.6)$ & 6.94 & 0.060 \\
\hline Antipsychotics & $7(2.0)$ & $301(98.0)$ & 2.00 & 0.420 \\
\hline Antiepileptics & $10(3.3)$ & $298(96.8)$ & 1.84 & 0.061 \\
\hline Benzodiazepines & $12(3.9)$ & $396(96.2)$ & 8.69 & $<0.00 I^{*}$ \\
\hline Warfarin & $3(1.0)$ & $309(99.0)$ & 1.16 & 0.520 \\
\hline Drugs for benign prostate hypertrophy (males only) & $\mathrm{I}(0.8)$ & $125(99.2)$ & 1.82 & 0.330 \\
\hline Reflux drugs & $29(9.4)$ & $279(90.6)$ & 7.56 & 0.132 \\
\hline Laxatives & $8(2.6)$ & $300(97.4)$ & 1.60 & 0.124 \\
\hline Tranexamic acid & $\mathrm{I}(0.3)$ & $307(99.7)$ & 0.30 & 0.604 \\
\hline Incontinence drugs & $4(1.3)$ & $304(98.7)$ & 0.55 & 0.092 \\
\hline Parkinson drugs & $4(1.3)$ & $304(98.7)$ & 0.60 & 0.116 \\
\hline Drug treatment of metabolic syndrome & $10(3.2)$ & $302(96.8)$ & 2.05 & 0.105 \\
\hline Diuretics & $56(18.2)$ & $252(81.8)$ & 9.04 & $<0.00 I^{*}$ \\
\hline Nasal steroids & $8(2.6)$ & $300(97.4)$ & 3.80 & 0.170 \\
\hline Female hormones (females only) & $30(16.5)$ & $152(83.5)$ & 25.13 & $0.003^{*}$ \\
\hline \multicolumn{5}{|l|}{ Comorbidities } \\
\hline Diabetes & $36(11.5)$ & $276(88.5)$ & $4.8 \S$ & $<0.00 I^{*}$ \\
\hline Hypertension & $132(42.3)$ & $180(57.7)$ & $17.2 \S$ & $<0.00 I^{*}$ \\
\hline Ischemic heart disease & $24(7.8)$ & $285(92.2)$ & $3.8 \S$ & $0.001 *$ \\
\hline Heart failure & $12(3.9)$ & $294(96.1)$ & $1.1 \pi$ & $<0.00 I^{*}$ \\
\hline
\end{tabular}

(Continued) 
Table 5 (Continued).

\begin{tabular}{|l|l|l|l|l|}
\hline Daily Drug Intake & Yes, $\mathbf{n}(\%)$ & No, $\mathbf{n}(\%)$ & Background Population \% & p-value, Binomial Test \\
\hline Allergy & $93(30.5)$ & $212(69.5)$ & $19.5 \S$ & $<0.00 I^{*}$ \\
\hline Drug allergy (not ACEi) & $47(15.3)$ & & & \\
\hline Asthma & $31(10.0)$ & $280(90.0)$ & $7.6 \S$ & 0.075 \\
\hline
\end{tabular}

Notes: Daily drug intake for 308 patients, referred between 1999-2014 compared to the background population. §Data from Medstat.dk, ${ }^{24}$ IData from Christensen et al. ${ }^{25}$ $\mathrm{n}=$ number of patients. *Statistically significant result.

AE patients. Angioedema associated deaths are rare, but has been described as increasing due to the increased use of ACEi. ${ }^{43}$ Selection bias could play a role in the number of acute airway managements, since patients with head and neck AE are more likely to be referred to a tertiary care hospital, as it is potentially lethal. Patients with minor AE incidents in other locations are probably handled in general practice and thus never present in the hospital sector. Twelve patients presented with $\mathrm{AE}$ in the abdomen, but none of these patients presented with abdomen as the only afflicted area. This supports the assumption that single-area intraabdominal $\mathrm{AE}$ is underreported due to the difficulty in diagnostics. $^{17,44}$

Hospitalization and ER visit were observed in $43.2 \%$ and $40.3 \%$ of cases, respectively, establishing how $\mathrm{AE}$ is a patient group that requires acute resources in the medical care system. A study revealed increased annual number of admissions and costs due to AE during the period of 1998 to 2005 . $^{45}$

Prior studies reporting a great variation in admission rates of $25-84 \%$ for all $\mathrm{AE}$ types. ${ }^{39}$ These data do not indicate a dissimilarity in hospitalizations of primary $\mathrm{AE}$ compared to general AE. Older age, and ACEi-induced AE were reported as parameters significantly associated with admission.

Anti-allergic standard treatment (antihistamines, corticosteroids, adrenaline) was most frequently administered to patients in this cohort, despite the fact that these drugs are ineffective for patients with non-histaminergic AE. ${ }^{17}$ Treatment of AE is based on pathophysiology, but this is rarely possible in the acute setting to determine the underlying mediator of AE. Many of the patients in this study were reported with good effect of antihistamines and corticosteroids even though none showed clinical signs of urticaria. The plausible explanation is a combination of factors: some of these patients have histaminergic $\mathrm{AE}$ and respond to treatment, and for $\mathrm{AE}$ the swelling is self- limiting, and this can lead to the wrong conclusion of a response to anti-allergic therapy.

Today the first-line treatment of acute AE is antihistamines, corticosteroids and if necessary, adrenalin. This favours the larger group of patients with histaminergic AE. Crochet et al revealed a 45-fold higher mortality risk for nonhistaminergic compared to histaminergic patients. ${ }^{18}$ This could be due to the first-line treatment targeting histaminergic- and not non-histaminergic patients. In this study, 24 patients were treated with other drugs than the anti-allergic drugs. Six ACEi-induced AE patients, three idiopathic AE, and two AE caused by physical stimuli were treated off the label with tranexamic acid or icatibant. One patient with $\mathrm{AE}$ caused by physical stimuli was treated with attenuated androgens and C1-INH concentrate. The efficacy was unclear from the medical record. $\mathrm{C} 1-\mathrm{INH}$ concentrate, icatibant, attenuated androgens and tranexamic acid approved for $\mathrm{C} 1-\mathrm{INH}-$ HAE, has shown promising results for other patients with non-histaminergic AE. ${ }^{2,41,46,48}$ Mansi et al found a reduction in symptoms and severity in patients with idiopathic nonhistaminergic AE treated with tranexamic acid, especially in long-term prophylaxis for patients with recurrent severe $\mathrm{AE}$ attacks. $^{2}$ Baş et al found a significant reduction in time to complete resolution in the acute phase for ACEi-induced AE patients treated with icatibant compared to standard therapy (from 27.1- to 8.0 hours). ${ }^{46}$ However, this was not confirmed in subsequent studies. ${ }^{49,50}$ Fresh frozen plasma has previously been used for patients with C1-INH-HAE, but in the western world, it is rarely used due to more effective medication being available. ${ }^{7}$ Greve et al found a positive effect of C1-INH concentrate for ACEi-induced AE compared to a control group and an ongoing randomized doubled blinded clinical trial is currently investigating the same. ${ }^{51,52}$

Our study revealed a significantly higher prevalence of comorbidities in the cohort compared to the background population. Comorbidities such as diabetes, hypertension, asthma, ischaemic heart disease, heart failure and allergies were also significantly associated with being admitted to 
a hospital due to AE. ACEi-induced $\mathrm{AE}$ and older age were also significantly associated with being admitted. Many patients receive ACEi due to the associated comorbidities.

The main limitation of the study is the retrospective design and the differences in evaluations by clinicians. One hundred and thirty-two (17\%) patients were excluded due to insufficient data. The percentage might influence the scientific findings. The study has no control group, and comparison to the background population did not adjust for age and sex due to insufficient data.

\section{Conclusion}

In this study, more than one-third of patients had histaminergic AE. This establishes how histaminergic AE does often occur without hives. Our study found idiopathic AE as the most frequent type of primary AE. However, little is known about the pathophysiology of this heterogenic group of patients. Forty percent of patients had druginduced AE, with ACEi being the most frequent causative agent. Drugs labelled for HAE are sparsely used off-label in selected cases in the clinical setting. AE of the head and neck area, which can become life-threatening, occurred in the majority of patients. Six of seven patients needing acute airway management had ACEi-induced AE as an underlying factor. Female sex and smoking were confirmed to be risk factors of primary AE. Patients with ACEi as a causative agent have a significant increased risk of admission compared to other types of primary AE.

\section{Abbreviations}

$\mathrm{AE}$, angioedema; $\mathrm{HAE}$, hereditary angioedema; $\mathrm{AAE}$, acquired angioedema; C1-INH-HAE, hereditary angioedema with complement $\mathrm{C} 1$-inhibitor deficiency; C1-INH-AAE, acquired angioedema with complement $\mathrm{C} 1$-inhibitor deficiency; ACEi, angiotensin-converting enzyme inhibitor; ER, emergency room; CI, confidence interval; OR, odds ratio.

\section{Data Sharing Statement}

The dataset generated and analysed during the current study is available from the corresponding author on reasonable request.

\section{Ethics Approval}

This study was approved by the local ethics committee as applicable under Danish law (record S-20140165) and by the Danish Data Protection Agency (journal 2008580035).

\section{Acknowledgments}

Institutions where the work was performed are as follows: collection of data: Department of Dermatology and Allergy Centre, Odense University Hospital, J.B. Winsloevsvej 4, Entrance 142, 5000 Odense C, Denmark, with associated physicians: Georg Authried, Sumangali Chandra Prasad, Kristine Appel U. Pallesen, Kawa Khaled Ajgeiy, Shailajah Kamaleswaran, and professor Anette Bygum; analysis and statistics: Department of Otorhinolaryngology, Head \& Neck Surgery and Audiology, Rigshospitalet, University of Copenhagen, with associated physicians: MBBS Amalie Hartvig Pall and Dr. Eva Rye Rasmussen, MD. PhD.

\section{Author Contributions}

All authors made substantial contributions to conception and design, acquisition of data, or analysis and interpretation of data; took part in drafting the article or revising it critically for important intellectual content; gave final approval of the version to be published; and agree to be accountable for all aspects of the work.

\section{Funding}

Grant IIR-DNK-001219 and Sp-DNK-187 from Shire ${ }^{\circledR}$ was partly given in support of this study.

\section{Disclosure}

A. Pall has received one travel grant from CSL Behring. A. Bygum has been involved in clinical research and educational events involving CSL-Behring, Dyax, BioCryst and Shire/Takeda, reports payment for educational activities from Novartis, and grants and personal fees from CSL Behring and Shire (now part of Takeda), and personal fees from Novartis, outside the submitted work. E. Rasmussen has received research funding, travel grants and speakers fees from Shire, CSL Behring and Viropharma, reports personal fees from Shire-Takeda, outside the submitted work, and served on an advisory board on hereditary angioedema treatment for Shire-Takeda. The authors report no other possible conflicts of interest in this work.

\section{References}

1. Rasmussen E, Bindslev-Jensen C, Bygum A. Angioedema - assessment and treatment. Tidsskr nor Legeforen. 2012;20(20):2391-2395. doi:10.4045/tidsskr.12.0470

2. Mansi M, Zanichelli A, Coerezza A, et al. Presentation, diagnosis and treatment of angioedema without wheals: a retrospective analysis of a cohort of 1058 patients. J Intern Med. 2015;277(5):585-593. doi:10.1111/joim. 12304 
3. Champion RH, Roberts SOB, Carpenter RG, Roger JH. Urticaria and angio-oedema. Br J Dermatol. 1969;81(81):588-597. doi:10.1111/ j.1365-2133.1969.tb16041.x

4. Zingale LC, Beltrami L, Zanichelli A, et al. Angioedema without urticaria: a large clinical survey. CMAJ. 2006;175(9):1065-1070. doi:10.1503/cmaj.060535

5. Kibsgaard L, Lefevre AC, Deleuran M, Vestergaard C. A case series study of eighty-five chronic spontaneous urticaria patients referred to a tertiary care center. Ann Dermatol. 2014;26(1):73-78. doi:10.5021/ ad.2014.26.1.73

6. Depetri F, Tedeschi A, Cugno M. Angioedema and emergency medicine: from pathophysiology to diagnosis and treatment. Eur J Intern Med. 2019;59(May):8-13. doi:10.1016/j.ejim.2018.09.004

7. Cicardi M, Aberer W, Banerji A, et al. Classification, diagnosis, and approach to treatment for angioedema: consensus report from the hereditary angioedema international working group. Eur J Allergy Clin Immunol. 2014;69(5):602-616. doi:10.1111/all.12380

8. Bafunno V, Firinu D, D'Apolito M, et al. Mutation of the angiopoietin-1 gene (ANGPT1) associates with a new type of hereditary angioedema. $J$ Allergy Clin Immunol. 2018;141 (3):1009-1017. doi:10.1016/j.jaci.2017.05.020

9. Bork K, Wulff K, Steinmüller-Magin L, et al. Hereditary angioedema with a mutation in the plasminogen gene. Eur J Allergy Clin Immunol. 2018;73(2):442-450. doi:10.1111/all.13270

10. Dewald G, Bork K. Missense mutations in the coagulation factor XII (Hageman factor) gene in hereditary angioedema with normal $\mathrm{C} 1$ inhibitor. Biochem Biophys Res Commun. 2006;343(4):1286-1289. doi:10.1016/j.bbrc.2006.03.092

11. Bork K, Wulff K, Rossmann H, et al. Hereditary angioedema cosegregating with a novel kininogen 1 gene mutation changing the N-terminal cleavage site of bradykinin. Allergy Eur J Allergy Clin Immunol. 2019;74(12):2479-2481. doi:10.1111/all.13869

12. Zanichelli A, Arcoleo F, Barca MP, et al. A nationwide survey of hereditary angioedema due to $\mathrm{C} 1$ inhibitor deficiency in Italy. Orphanet J Rare Dis. 2015;10(1):11. doi:10.1186/s13023-015-0233-x

13. Bygum A. Hereditary angio-oedema in Denmark: a nationwide survey. Br J Dermatol. 2009;161(5):1153-1158. doi:10.1111/j.13652133.2009.09366.x

14. Gobert D, Paule R, Ponard D, et al. A nationwide study of acquired C1-inhibitor deficiency in France. Medicine (Baltimore). 2016;95 (33):e4363. doi:10.1097/MD.0000000000004363

15. Bygum A, Vestergaard H. Acquired angioedema - Occurrence, clinical features and associated disorders in a Danish nationwide patient cohort. Int Arch Allergy Immunol. 2013;162(2):149-155. doi:10.1159/000351452

16. Moreau ME, Garbacki N, Molinaro G, Brown NJ, Marceau F, Adam A. Survey review the kallikrein-kinin system: current and future pharmacological targets. J Pharmacol Sci. 2005;38(1):6-38. doi:10.1254/jphs.SRJ05001X

17. Hirschy RA, Shah T, Davis T, Rech MA. Treatment of life-threatening ACE-inhibitor-induced angioedema. Adv Emerg Nurs J. 2018;40(4):267-277. doi:10.1097/TME.0000000000000211

18. Crochet J, Lepelley M, Yahiaoui N, et al. Bradykinin mechanism is the main responsible for death by isolated asphyxiating angioedema in France. Clin Exp Allergy. 2018;49(September 2018):252-254. doi:10.1111/cea.13297

19. Prior N, Remor E, Pérez-Fernández E, et al. Psychometric field study of hereditary angioedema quality of life questionnaire for adults: HAE-QoL. J Allergy Clin Immunol Pract. 2016;4(3):464-473. doi:10.1016/j.jaip.2015.12.010

20. Nedelea I, Deleanu D. Isolated angioedema: an overview of clinical features and etiology (review). Exp Ther Med. 2018;17 (4):1068-1072. doi:10.3892/etm.2018.6982

21. Bork K, Staubach-Renz P, Hardt J. Angioedema due to acquired C1-inhibitor deficiency: spectrum and treatment with $\mathrm{C} 1$-inhibitor concentrate. Orphanet J Rare Dis. 2019;143(2):AB42.
22. Craig T, Zuraw B, Longhurst H, et al. Long-term outcomes with subcutaneous C1-inhibitor replacement therapy for prevention of hereditary angioedema attacks. J Allergy Clin Immunol Pract. 2019;7(6):1793-1802.e2. doi:10.1016/j.jaip.2019.01.054

23. Cicardi M, Banerji ABF, Malbrán A, et al. Icatibant, a new bradykinin-receptor antagonist, in hereditary angioedema. $N \mathrm{Engl}$ $J$ Med. 2010;363(6):532-541. doi:10.1056/NEJMoa0906393

24. Sundhedsdatastyrelsen. Medstat.dk [Internet]. [cited Mar 20, 2019]. Available from: http://www.medstat.dk.

25. Christensen AI, Ekholm O, Davidsen M, Juel K. Sundhed Og Sygelighed 2010. 2010.

26. Kragh-Jakobsen AS, Haun Jesper B. Hjertesvigt [Internet]. [cited Apr 2, 2019]. Available from: http://www.hjertesvigt.dk.

27. Cicardi M, Zanichelli A. Acquired angioedema. Allergy Asthma Clin Immunol. 2010;6(1):1-5. doi:10.1186/1710-1492-6-14

28. Holm JPY, Ovesen T. Increasing rate of angiotensin-converting enzyme inhibitor-related upper airway angio-oedema. Dan Med J. 2012;59(6):A4449.

29. Kostis JB, Kim HJ, Rusnak J, et al. Incidence and characteristics of angioedema associated with enalapril. Arch Intern Med. 2005;165 (14):1637-1642. doi:10.1001/archinte.165.14.1637

30. Banerji A, Blumenthal KG, Lai KH, Zhou L. Epidemiology of ACE inhibitor angioedema utilizing a large electronic health record. J Allergy Clin Immunol Pract. 2017;5(3):744-749. doi:10.1016/j. jaip.2017.02.018

31. Rasmussen ER, Pottegård A, Bygum A, von Buchwald C, Homøe $\mathrm{P}$, Hallas J. Angiotensin II receptor blockers are safe in patients with prior angioedema related to angiotensin-converting enzyme inhibitors - a nationwide registry-based cohort study. J Intern Med. 2019;285(5):1-9. doi:10.1111/joim.12867

32. Kaplan AP. Angioedema. World Allergy Organ J. 2008;1(6):103-113. doi:10.1097/WOX.0b013e31817aecbe

33. Leeyaphan C, Kulthanan K, Jongjarearnprasert K, Dhana N. Druginduced angioedema without urticaria: prevalence and clinical features. J Eur Acad Dermatol Venereol. 2010;24(6):685-691. doi:10.1111/j.1468-3083.2009.03489.x

34. Kulthanan K, Jiamton S, Boochangkool K, Jongjarearnprasert K. Angioedema: clinical and etiological aspects. Clin Dev Immunol. 2007;2007:6-11. doi:10.1155/2007/26438

35. El Mekki AB, Chaib A, Kombich J. Drug induced angioedema: a rare side effect of simvastatin. Pan Afr Med J. 2017;26(7):213. doi:10.11604/pamj.2017.26.38.10312

36. Kuruvilla ME, Sanan N. Amlodipine-induced angioedema: an unusual complication of a common medication. Allergy Rhinol. 2018;6 (9):1-2.

37. Atik D, Büyükcam F, Yılmaz D, Işık B, Demir ÖF. Angioedema after the first dose of metformin. Am J Emerg Med. 2013;31(3):634.e5. doi:10.1016/j.ajem.2012.10.021

38. Krikorian RK, Quick A, Tal A. Angioedema following the intravenous administration of metoprolol. Chest. 1994;106(6):1922-1923. doi:10.1378/chest.106.6.1922

39. Tai S, Mascaro M, Goldstein NA. Angioedema: a review of 367 episodes presenting to three tertiary care hospitals. Ann Otol Rhinol Laryngol. 2010;119(12):836-841. doi:10.1177/000348941011901208

40. Madsen F, Attermann J, Linneberg A. Epidemiology of non-hereditary angioedema. Acta Derm Venereol. 2012;92 (5):475-479. doi:10.2340/00015555-1389

41. Eli M, Joseph M, Kuznik B, Menachem S. Chronic idiopathic angioedema: a single center experience. Int J Dermatol. 2014;53(10):e4217. doi:10.1111/ijd.12601

42. Megerian CA, Arnold JE, Berger M. Angioedema: 5 years' experience, with a review of the disorder's presentation and treatment. Laryngoscope. 1992;(102):256-260.

43. Kim SJ, Brooks JC, Sheikh J, Kaplan MS, Goldberg BJ. Angioedema deaths in the United States, 1979-2010. Ann Allergy Asthma Immunol. 2014;113(6):630-634. doi:10.1016/j.anai.2014.09.003 
44. Byrne TJ, Douglas DD, Landis ME, Heppell JP. Isolated visceral angioedema: an underdiagnosed complication of ACE inhibitors? Mayo Clin Proc. 2000;75(11):1201-1204. doi:10.4065/75.11.1201

45. Lin RY, Shah SN. Increasing hospitalizations due to angioedema in the United States. Ann Allergy Asthma Immunol. 2008;101 (2):185-192. doi:10.1016/S1081-1206(10)60208-6

46. Baş M, Greve J, Stelter K, et al. A randomized trial of icatibant in ACE-inhibitor-induced angioedema. $N$ Engl $J$ Med. 2015;372 (5):418-425. doi:10.1056/NEJMoa1312524

47. Cicardi M, Bergamaschini L, Zingale LC, Gioffré D, Agostoni A. Idiopathic nonhistaminergic angioedema. Am J Med. 1999;106 (6):650-654. doi:10.1016/S0002-9343(99)00123-0

48. Craig TJ, Bernstein JA, Farkas H, Bouillet L, Boccon-Gibod I. Diagnosis and treatment of bradykinin-mediated angioedema: outcomes from an angioedema expert consensus meeting. Int Arch Allergy Immunol. 2014;165(2):119-127. doi:10.1159/000368404
49. Sinert R, Levy P, Bernstein JA, et al. Randomized trial of icatibant for angiotensin-converting enzyme inhibitor-induced upper airway angioedema. J Allergy Clin Immunol Pract. 2017;5(5):1402-1409.e3. doi:10.1016/j.jaip.2017.03.003

50. Straka B, Ramirez C, Byrd J, et al. Effect of bradykinin receptor antagonism on ACE inhibitor-associated angioedema. J Allergy Clin Immunol. 2017;140(1):242-248.e2. doi:10.1016/j.jaci.2016.09.051

51. Greve J, Bas M, Hoffmann TK, et al. Effect of C1-esterase-inhibitor in angiotensin-converting enzyme inhibitor-induced angioedema. Laryngoscope. 2015;125(6):E198-202. doi:10.1002/lary.25113

52. Bas M. Randomized, double-blind, two arms, multicenter, phase III study of berinert for treatment of ACE induced angioedema [Internet]. Available from: https://clinicaltrials.gov/ct $2 /$ show/ NCT01843530 term $=$ complement $+\mathrm{C} 1 \&$ cond $=$ Angioedema\&cntry $=$ DE\&rank=3. Accessed June 22, 2020.

\section{Publish your work in this journal}

The Journal of Asthma and Allergy is an international, peer-reviewed open-access journal publishing original research, reports, editorials and commentaries on the following topics: Asthma; Pulmonary physiology; Asthma related clinical health; Clinical immunology and the immunological basis of disease; Pharmacological interventions and new therapies. The manuscript management system is completely online and includes a very quick and fair peer-review system, which is all easy to use. Visit http://www.dovepress.com/testimonials.php to read real quotes from published authors. 